staffing of first aid posts, and the duties of first aid workers, aro first dealt with, after which general directions are given for the use of dressings and treatment of injuries and burns. Injuries and their first aid treatment are then dealt with in detail of various regions of the body. Finally, some valuable hints are given for the treatment of patients who may bo suffering from fright, fear or nervous shock. The appropriate opium dosage to be used for cleansing burns and scalds is given in an appendix.

\section{Psychiatry in the Punjab}

IN his chairman's address at the inaugural meeting of the Indian Division of the Royal Medico-Psychological Association (J. Ment. Sci., 85, 381; 1939) Lieut.-Colonel C. J. Lodgo Patch gives a striking account of the inhuman treatment of the insane in India which has persisted down to the present day. During the last hundred years, though there have been flashes of intelligence, interest and humanity in the 'forties, 'fifties and 'sixties associated with the names of Honigberger, Smith and De Renzy, there have been frequent returns to a state of almost primeval darkness. On his appointment as medical superintendent of the Punjab Mental Hospital in 1922, Colonel Patch found a deplorablo state of affairs. Nearly all the malo patients wero allowed to go about stark nalied, handcuffs and fetters were applied on little or no provocation, and the patients were living in a reign of terror. His first act was to collect two hundredweight of handeuffs and send them in a bullock cart to the central jail. His next was to dismiss a swarm of undesirablo attendants, and then to remore the bolts and bars which gave the hospital the aspect of a prison. WVithin the last few months a new hospital has been built to Colonel Patch's designs on modern lines and not containing \& singlo bar, grill or grating. Throughout the whole of India, abuses in the treatment of the insane still exist, as is shown by the fact that Colonel Patch has admitted to his hospital hundreds of patients with scars of beatings, blisterings, bleedings and other brutalities administered to drive out the devil supposed to have taken possession of the madman's mind. There is therefore much that can be done in India by spreading knowledge of the nature, prophylaxis and treatment of insanity.

\section{Dust and Disease}

IN his inaugural thesis (Thèse de Paris, No. 522; 1939), Dr. André Assémat remarks that the inhalation of dust is the cause of various lesions in the respiratory system, but that the gravity of the pulmonary involvement is mainly due to its effect on the general condition. He adopts Teleky's classification of the modes of action of dust in the following eight groups : (1) A microchemical action giving rise to characteristic lesions, especially in the caso of silicosis and asbestosis. (2) An action which does not produce any changes in the lung until after intense and prolonged inhalation, as in the case of coal and non-siliceous mineral dust. (3) An action affecting the respiratory tract rather than the lung, as in the case of coarse wood dust, textiles and cereals. (4) A carcinogenic action caused by the dust of chromates, nickel and radioactive substances. (5) A sensitizing or allergic action. (6) A chemical action favouring the development of inflammatory processes. (7) An infective action when the dust is associated with micro. organisms and fungi, etc. (8) An intoxication of the system, as in the case of manganese. Apart from its own action, dust may bo an aggravating factor in the courso of lung disease. The tuberculosis problem is closely connected with that of pneumoconiosis, and especially silicosis, which always aggravates the prognosis. Occupational diseases due to dust represent an important cause of temporary or permanent incapacity for work and therefore have a bad effect on the general activity of a country. Before studying the means of repairing the damage done by certain forms of dust, it is important to secure the prevention of these diseases by the use of all the methods capable of protecting tho worker, such as interception of the dust at its source, ventilation and the wearing of masks. The medical officer should play an im. portant part in the engagement of workers and should reject any who suffer from pulmonary disease, especially tuberculosis, as well as those with a defective naso-pharynx. After enrolment, the workers should undergo periodical examination, and skiagrams should be taken and kept for future reference.

\section{Destruction of Rabbits}

IN days of war, our stock of wild rabbits has value as a food-supply, but the experience of the War of 1914-18 was that the absence of game-keepers and rabbit-trappers permitted an excessive increase; and their food value did not balance the damage to crops thoy did. Accordingly, in 1917 it was found necessary to legislate for tho prevention of damage by rabbits, tho emergency legislation being repealed in 1921. The experience of the last war is likely to be repeated in the present conflict, but now the situation is more favourable from the nation's point of view, since there has been on the statute book since July of this year a Prevention of Damage by Rabbits Act, which offers facilities for dealing with the rabbit pest. For the successful carrying out of the obligations of the Act, tho Universities Federation for Animal Welfare has published a rovised and enlarged edition of its "Instructions for Dealing with Rabbits". This 20-page pamphlet gives much information about rabbit-proof fencing, fumigation, long-netting, ferreting, shooting, catching with dazzlo-light (an impracticable method under 'black-out' conditions), cat ching in enclosures, and it naturally omits reference to the less humane method of the steel-trap against which the Federation has waged constant warfare. The pamphlet is a handy and reliable guide to methods of keeping down rabbits, and its value is increased by the inclusion of the text and a brief explanation of the provisions of the now Act. Single copies of the pamphlet may be had free on enclosing a stamped and addressed quarto envelope to UFAW, Gordon House, 29 Gordon Square, London, WV.C.1, or larger quantities will be supplied at cost price ( $3 d$, each). 